\title{
Budget impact analysis of darolutamide for treatment of nonmetastatic castration-resistant prostate cancer
}

\author{
Sreevalsa Appukkuttan, MPH; Ryan Farej, BS; LaStella Miles, MS; Molly Purser, PhD; and Lonnie Wen, RPh, PhD
}

\section{What is already known about this subject}

- Prostate cancer is one of the most common types of cancer among American men.

- This disease has many facets (e.g., nonmetastatic, metastatic, castrationresistant), a high economic burden, and significant mortality risk.

- Darolutamide, an androgen receptor inhibitor approved for nonmetastatic castration-resistant prostate cancer (nmCRPC), has a novel chemical structure that may also have safety, tolerability, and efficacy advantages for men with nmCRPC.

\section{What this study adds}

- This is the first economic model estimating the budget impact of darolutamide in nmCRPC.

- Analyses are presented for multiple populations (e.g., overall nmCRPC, highrisk nMCRPC, and Medicare-eligible $\mathrm{nm}$ CRPC).

- Over a 5-year period, adding darolutamide to a U.S. payer formulary for nmCRPC results in a manageable increase in a payer's budget (year 1 : $2.23 \%$ ) that trends downward and is cost-saving by year $5(-0.51 \%)$.

\section{ABSTRACT}

BACKGROUND: Darolutamide, a structurally distinct androgen receptor inhibitor approved for the treatment of men with nonmetastatic castration-resistant prostate cancer (nmCRPC), has been shown to increase metastasis-free survival among men with nmCRPC compared with placebo. This treatment has a novel chemical structure that may also have safety, tolerability, and efficacy advantages for men with nmCRPC.

OBJECTIVE: To estimate the projected budget impact of including darolutamide on a U.S. payer formulary as a treatment option for men with nmCRPC.

METHODS: A budget impact model was developed to evaluate darolutamide for nmCRPC for a hypothetical 1-millionmember plan over a 5-year period. Costs (drug acquisition, drug administration, and treatment-related adverse events [AEs]) were estimated for 2 scenarios: with and without darolutamide treatment for nmCRPC. The budget impact of darolutamide was calculated as the difference in costs for these 2 scenarios. An analysis for high-risk nmCRPC also was conducted. The model included treatments recommended by the National Comprehensive Cancer Network (e.g., apalutamide and enzalutamide) and potential comparators that are used but are not specifically indicated for nmCRPC. All treatments were assumed to be administered in combination with a weighted average androgen deprivation therapy comparator (consisting of luteinizing hormone-releasing hormone [LHRH] agonists, LHRH antagonists, and firstgeneration antiandrogens). Market share estimates were derived from interviews with physicians treating men with nmCRPC. The

\section{Author affiliations \\ Sreevalsa Appukkuttan, MPH; Ryan Farej, BS; and Lonnie Wen, RPh, PhD, Bayer Health Care, Whippany, NJ. LaStella Miles, MS, and Molly Purser, PhD, RTI Health Solutions, Research Triangle, NC.}

AUTHOR CORRESPONDENCE:

Sreevalsa Appukkuttan, sreevalsa.appukkuttan@bayer.com

J Manag Care Spec Pharm. 2021;27(2):166-74

Copyright $\odot 2021$, Academy of Managed Care Pharmacy. All rights reserved.

model includes grade 3-4 AEs, and the rates were obtained from clinical trial data. Costs were taken from publicly available sources and varied in a one-way sensitivity analysis.

RESULTS: For a plan with 1 million lives, there were approximately 90 incident cases of nmCRPC (46 high risk) each year, with 332 (109 high risk) treatment-eligible cases by year 5 . Darolutamide's market share increased from $3.6 \%$ in year 1 to $18 \%$ in year 5 . Given the utilization of other agents, introducing darolutamide along with other targeted therapies was predicted to increase the total budget by $\$ 158,640$ (\$0.0132 per member per month [PMPM]) in year 1 , which decreased over time to a cost savings of $\$ 149,240$ ( $\$ 0.0124$ PMPM) by year 5 . The scenario with darolutamide showed reduced AE costs each year. Similar results were observed for the high-risk nmCRPC population. 
CONCLUSIONS: Adding darolutamide to a U.S. payer formulary for the treatment of nmCRPC can result in a manageable increase in the budget that is partly offset by AE costs in the first 4 years, followed by a cost savings by year 5 .

Prostate cancer is one of the most common cancers among American men, with approximately 191,930 new cases and 33,330 deaths projected for 2020. ${ }^{1}$ Men with nonmetastatic castration-resistant prostate cancer (nmCRPC) have disease that has progressed despite castrate levels of serum testosterone with no evidence of metastases by imaging. ${ }^{2}$ The economic burden of nonmetastatic or localized prostate cancer in the United States has been estimated to be $\$ 46,193$ per patient over 5 years and $\$ 110,993$ per patient over 10 years. $^{3}$ As castration-resistant prostate cancer (CRPC) progresses, there is a 4-fold increase in all-cause health care resource use and costs. Thus, treatments that delay progression to metastasis will delay the health care burden associated with metastatic CRPC. ${ }^{4}$

National Comprehensive Cancer Network guidelines recommend androgen deprivation therapy (ADT) for patients with prostate-specific antigen doubling time (PSADT) of more than 10 months and secondary hormone therapy for patients with PSADT of 10 months or less. ${ }^{2}$ Darolutamide, a structurally distinct androgen receptor inhibitor, has been shown to increase metastasis-free survival among men with nmCRPC compared with placebo, with a low incidence of treatment-related adverse events (AEs). ${ }^{5,6}$ In the ARAMIS trial, the median metastasis-free survival was 40.4 months for darolutamide versus 18.4 months for placebo. ${ }^{5}$

Darolutamide was approved in July 2019 by the U.S. Food and Drug Administration (FDA) for the treatment of men with nmCRPC. ${ }^{7}$ The novel chemical structure may present safety, tolerability, and efficacy advantages for men with nmCRPC because of its low penetration of the blood-brain barrier. ${ }^{5,8}$ The purpose of this study is to estimate the projected budget impact of including darolutamide on a U.S. payer formulary as a treatment option for men with nmCRPC.

\section{Methods}

\section{MODEL STRUCTURE AND POPULATION}

An economic model was developed in Excel (Microsoft, Redmond, WA) to estimate costs associated with nmCRPC in the United States.
Costs were estimated for a scenario in which darolutamide was not available (scenario 1) for nmCRPC and one in which darolutamide was available (scenario 2) and used to treat nmCRPC. The estimated budget impact of darolutamide was based on a comparison of these scenarios. The model included calculations estimating drug acquisition, administration, and AE costs. Costs were estimated based on microlevel unit costs and resources.

The size of the treated population was estimated by funneling down the total population of a U.S. health plan to the population of interest. In the base case, the population of interest was defined as adult males (aged 18 years or older) with nmCRPC (Figure 1). The initial modeled population was based on incident cases of nmCRPC.

In addition to this base-case population, the model included options to consider analyses focused on the subset of adult males with high-risk nmCRPC, defined by a PSADT $\leq 10$ months, and the subset of patients eligible for Medicare (i.e., those aged 65 years and older).

\section{TREATMENT OPTIONS}

Based on current treatment practices, the model included multiple treatments used to lower levels and production of testosterone and stunt cancer growth. Androgen deprivation therapy was included in the model as the standard of care and was composed of luteinizing hormone-releasing hormone (LHRH) agonists (leuprolide, goserelin, triptorelin), LHRH antagonists (degarelix), and antiandrogens (bicalutamide, flutamide, nilutamide) available in the United States at the time of model development. ${ }^{8}$ All other treatments in the model (darolutamide, apalutamide, enzalutamide, and abiraterone acetate [AA] plus prednisone [offlabel for $\mathrm{nmCRPC}]$ ) were administered in combination with a weighted average ADT.

\section{PERSPECTIVE, TIME HORIZON, AND DISCOUNTING}

The model considered the perspective of a third-party payer in the United States. As recommended by the International Society for Pharmacoeconomics and Outcomes Research's (ISPOR's) Task Force on Good Research Practices, ${ }^{10}$ analyses can be conducted for multiple time horizons and up to 5 years (e.g., 1 year, 2 years) following darolutamide approval. The model did not include discounting (all results are presented undiscounted), which is standard practice and consistent with ISPOR guidelines. ${ }^{10}$

\section{INPUTS}

Population. The modeled population began with an assumed 1,000,000-member plan (Figure 1). The percentage of the plan population aged $\geq 18$ years $(77.8 \%)$ and the percentage of adult males (48.8\%) were estimated from projected 
age groups and sex composition of the U.S. population in 2020 from the U.S. Census Bureau. ${ }^{11}$ The incidence of nmCRPC (0.0239\%) was estimated from Surveillance, Epidemiology, and End Results (SEER) cancer statistics based on the projected number of incident cases of nmCRPC in the United States in 2020 provided by Bayer (data on file; March 2019) and the projected male population aged $\geq 18$ years in 2020 from the U.S. Census Bureau. ${ }^{11}$

The percentage of patients with high-risk nmCRPC (50.2\%) was estimated from SEER cancer statistics based on the projected number of high-risk cases among the projected number of incident cases of nmCRPC in 2020 provided by Bayer (data on file; March 2019). The default percentage of Medicare-eligible patients (76.0\%) was obtained from a qualitative study among patients with nmCRPC. ${ }^{12}$

In analyses for time horizons beyond 1 year, the model considers changes in the population size. The annual percentage increase in population size was calculated based on population projections in 2020 and 2030 from the U.S. Census Bureau, ${ }^{13}$ assuming a linear increase over time. Projections for the age group $\geq 18$ years were used to calculate the value for the overall population $(0.8 \%)$, and projections for the age group $\geq 65$ years were used to calculate the value for the Medicare-eligible population (3.0\%).

The default percentage of patients who left the target population each year (e.g., those who develop metastases or die) was assumed to be $16.5 \%$ in the overall population based on a systematic review of the CRPC population, which reported that $33 \%$ of patients with nmCRPC could expect to develop metastases within 2 years. ${ }^{14}$

The value for the high-risk population was obtained from a dynamic disease progression model for prostate cancer that reported that $39 \%$ of high-risk nmCRPC patients progress

\section{FIGURE 1 Overall nmCRPC Population Funnel}

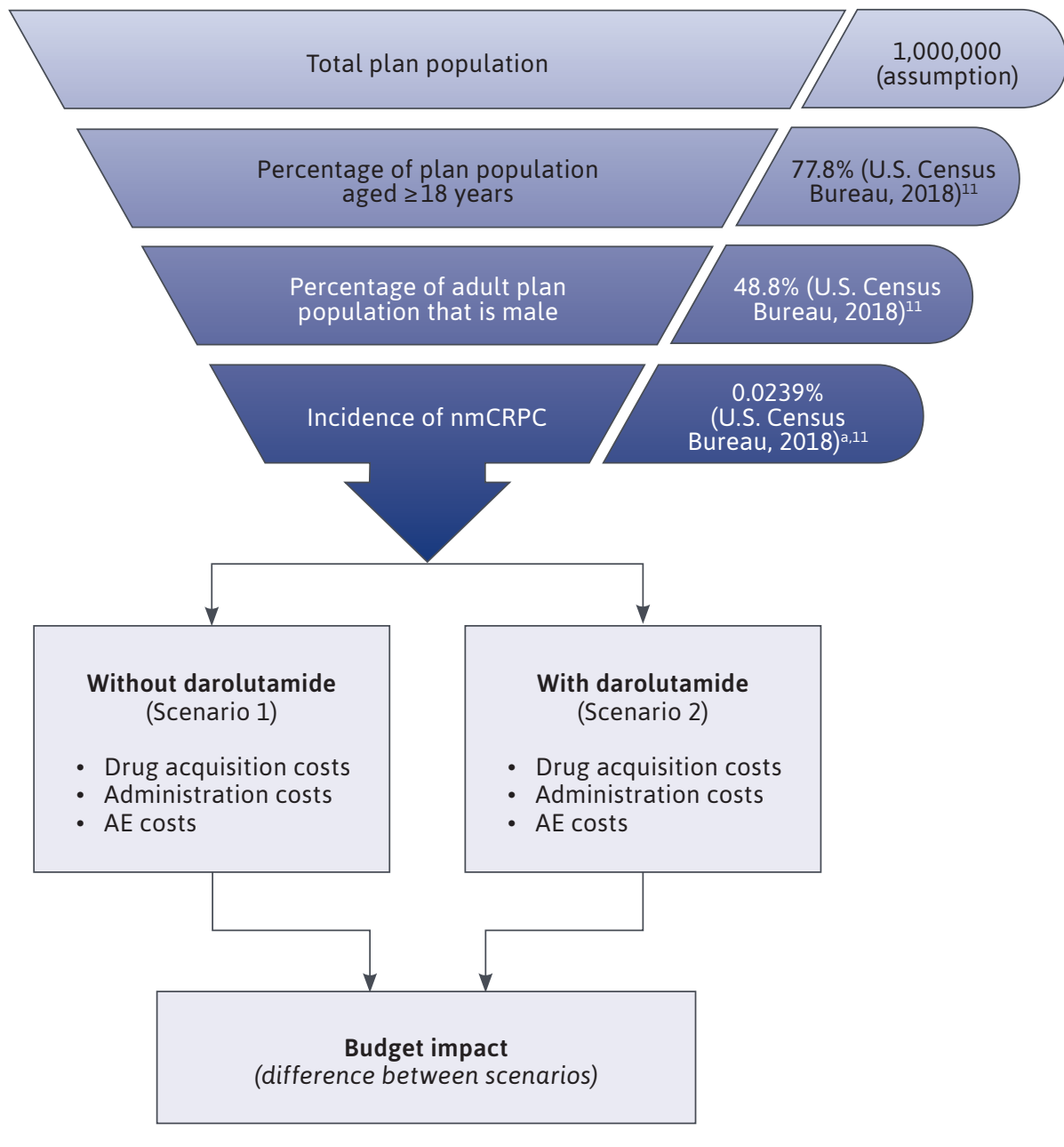

aBayer, data on file, $2019 \mathrm{~b}$.

$A E=$ adverse event; $n m C R P C=$ nonmetastatic castration-resistant prostate cancer; U.S. = United States.

to metastatic disease each year. ${ }^{15}$ The percentage of patients who left the population each year was not applied to the incident cases in the model year, and patients who left the target population in a given year were excluded from the starting population in the following year.

Market Share. The proportion of patients receiving each treatment option in the model was based on market share inputs for the scenarios with and without darolutamide. Data for these inputs were based on online interviews conducted among certified physicians who treat prostate cancer patients. Respondents were screened to ensure that they were boardcertified or board-eligible in medical/ hematology oncology or urology, spent at least $60 \%$ of their time in clinical practice or direct patient care, and saw at least 20 prostate cancer patients in the past 6 months. Sample data were collected from 75 oncologists and 


\section{TABLE 1 Base-Case Results}

\begin{tabular}{|c|c|c|c|c|c|}
\hline Result & Year 1 & Year 2 & Year 3 & Year 4 & Year 5 \\
\hline Incident nmCRPC cases & 91 & 91 & 92 & 93 & 93 \\
\hline Treatment-eligible nmCRPC cases & 91 & 167 & 231 & 286 & 332 \\
\hline \multicolumn{6}{|l|}{ Costs without darolutamide (\$) } \\
\hline Annual drug acquisition & $7,051,992$ & $13,378,938$ & $19,077,085$ & $24,231,342$ & $28,916,406$ \\
\hline Annual AE & 61,874 & 116,138 & 163,920 & 206,188 & 243,769 \\
\hline Total annual & $7,113,867$ & $13,495,076$ & $19,241,005$ & $24,437,530$ & $29,160,175$ \\
\hline Total PTMPM & $6,549.61$ & $6,741.55$ & $6,933.48$ & $7,125.42$ & 7,317.35 \\
\hline Total PMPM & 0.5928 & 1.1246 & 1.6034 & 2.0365 & 2.4300 \\
\hline \multicolumn{6}{|l|}{ Costs with darolutamide (\$) } \\
\hline Annual drug acquisition & $7,211,768$ & $13,585,765$ & $19,242,317$ & $24,285,395$ & $28,804,744$ \\
\hline Annual AE & 60,739 & 109,850 & 149,386 & 181,037 & 206,192 \\
\hline Total annual & $7,272,507$ & $13,695,615$ & $19,391,703$ & $24,466,432$ & $29,010,935$ \\
\hline Total PTMPM & $6,695.67$ & $6,841.73$ & $6,987.79$ & $7,133.84$ & $7,279.90$ \\
\hline Total PMPM & 0.6060 & 1.1413 & 1.6160 & 2.0389 & 2.4176 \\
\hline \multicolumn{6}{|l|}{ Difference in costs (budget impact) (\$) } \\
\hline Annual drug acquisition & 159,775 & 206,827 & 165,231 & 54,053 & $-111,662$ \\
\hline Annual AE & $-1,135$ & $-6,288$ & $-14,534$ & $-25,151$ & $-37,578$ \\
\hline Total annual & 158,640 & 200,539 & 150,697 & 28,901 & $-149,240$ \\
\hline Total PTMPM & 146.06 & 100.18 & 54.30 & 8.43 & -37.45 \\
\hline Total PMPM & 0.0132 & 0.0167 & 0.0126 & 0.0024 & -0.0124 \\
\hline
\end{tabular}

$A E=$ adverse event; $n m C R P C=$ nonmetastatic castration-resistant prostate cancer; $P M P M=$ per member per month; PTMPM=per treated member per month.

72 urologists who reported their current regimen utilization for patients treated for nmCRPC. The physicians were also askedtoconsiderafuturescenariothatincludeddarolutamide along with the current regimens to allow for an assessment of future market shares (Bayer, data on file; January 2019). The market share values are shown in Supplementary Tables 1-6 (available in online article).

Costs. Wholesale acquisition costs (WACs) for the drugs included in the model were obtained from RED BOOK Online. ${ }^{16}$ Monthly and annual treatment costs for each drug were calculated based on product-label dosing and are shown in Supplementary Table 7 (available in online article). Administration costs were included in the model as physician visits plus injection costs for treatments that must be administered under the supervision of a physician or by a health care professional only. Unit costs for physician visits (\$45.77) and injections (\$16.94) were obtained from the Medicare Physician Fee Schedule of the Resource-Based Relative Value Scale. ${ }^{17}$ However, this analysis does not report administration costs, as the modeled treatments that would be administered by a health care professional (i.e., leuprolide, goserelin, triptorelin, and degarelix) are not assigned any of the market share.

The analysis includes grade 3-4 AEs that occurred in at least $5 \%$ of patients for at least 1 modeled treatment (excluding ADT). Based on this criterion, the AEs included in the analysis were hypertension, rash, and hypokalemia. It is assumed that the management of all these events would incur hospitalization costs based on the definitions of grade 3 and grade 4 events from Common Terminology Criteria for Adverse Events. ${ }^{18}$ The incidence of AEs associated with ADT was not considered in the model, as all regimens include ADT and it was assumed that ADT-related AE costs would be the same for all regimens. Therefore, the model only considered AEs for apalutamide, enzalutamide, AA+ prednisone, and darolutamide.

Treatment-specific AE rates were obtained from clinical trial data ${ }^{5,19-21}$ and multiplied by treatment and management costs obtained from the Healthcare Cost and Utilization Project ${ }^{22}$ to estimate annual treatment-specific AE costs shown in Supplementary Tables 8 and 9 (available in online 


\section{FIGURE 2 Total Annual Budget Impact with Darolutamide in Nonmetastatic Castration-Resistant Prostate Cancer}

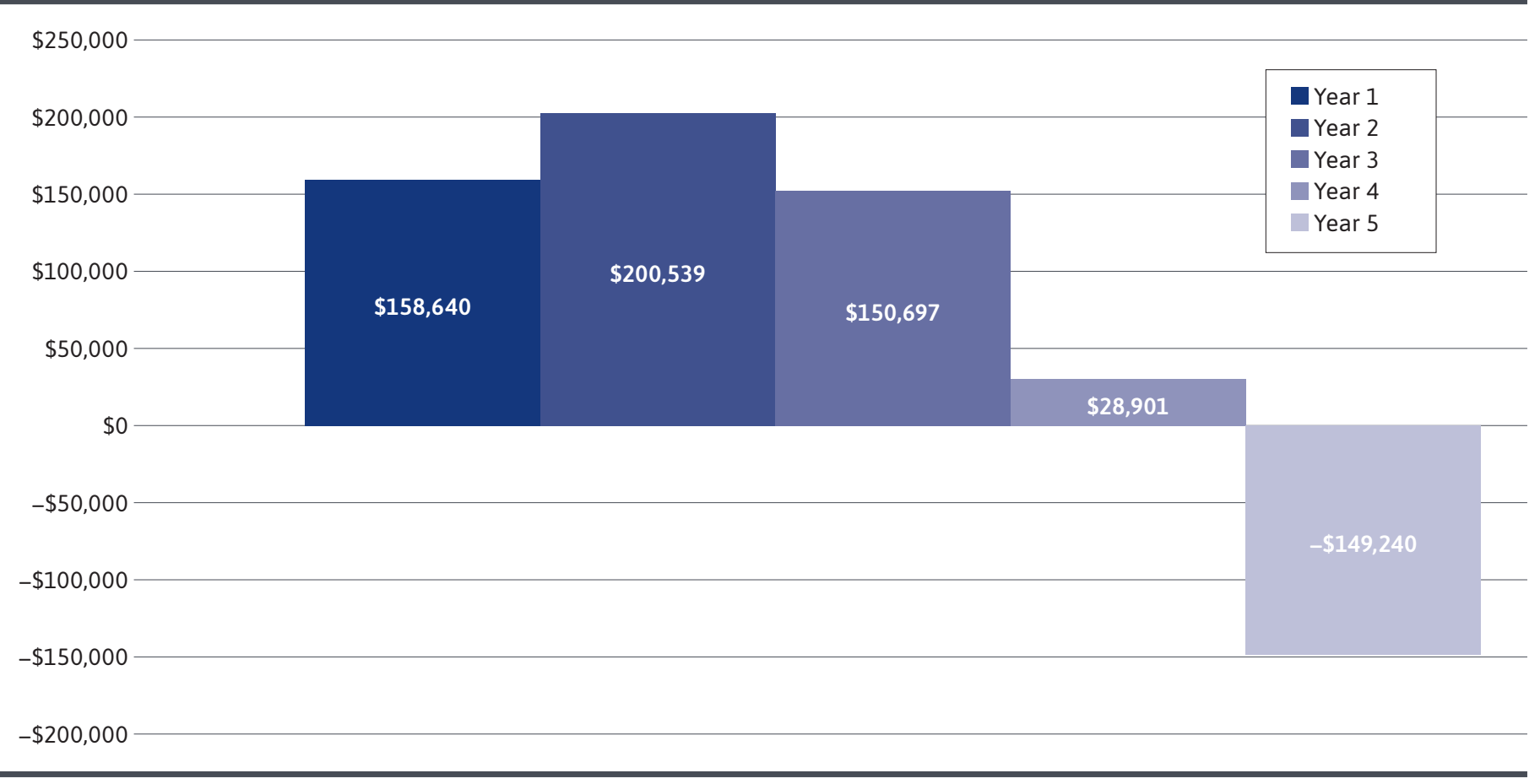

article). All costs were inflated to 2019 U.S. dollars using the medical care component of the Consumer Price Index from the U.S. Bureau of Labor Statistics. ${ }^{23}$

\section{ASSUMPTIONS}

The following assumptions in the model were held:

- Some treatments in the model were not indicated for the nmCRPC population. Therefore, the dosing and administration schedules for these comparators may be assumed to be equivalent to the approved usage in other prostate cancer populations (e.g., advanced or metastatic disease): - Dosing and cycle details for leuprolide, ${ }^{24}$ goserelin, ${ }^{25}$ triptorelin, ${ }^{26}$ and degarelix ${ }^{27}$ were based on their approved use in advanced prostatic cancer.

- Dosing and cycle details for $\mathrm{AA}+$ prednisone $^{28}$ were based on their approved use in the metastatic CRPC population.

- All treatments were assumed to be administered in combination with a weighted average ADT (based on the ADT options included in the model).

- The total population size was based on an assumed 1,000,000-member plan.
- The incidence of grade 3-4 AEs for ADT was not considered in the model, as all regimens included ADT; thus, it was assumed that ADT-related AE costs would be the same for all treatments.

- All grade 3-4 AEs included in the model were assumed to result in hospitalization.

- Treatment duration was not explicitly included in the model. However, patients were assumed to remain on treatment until disease progression. Thus, treatment duration was implied via the percentage of patients who leave the target population each year. The model made no assumptions about the efficacy of treatments.

\section{Results}

\section{BASE CASE}

In the base-case analysis, the model population started with an estimated 91 new cases of nmCRPC and grew to approximately 332 treatment-eligible nmCRPC patients by year 5 (Table 1). Total costs increased over time in the modeled time horizon, which coincided with the growth of the treated population in the model and the decrease in the 


\section{FIGURE 3 Tornado Diagram}

\begin{tabular}{|c|c|c|c|c|c|c|c|}
\hline$-\$ 150,000$ & $-\$ 100,000$ & $-\$ 50,000$ & \multicolumn{2}{|c|}{$\$ 0$} & $\$ 50,000$ & $\$ 100,000$ & $\$ 150,000$ \\
\hline Darolutamide drug acquisition cost & $-91,642$ & & & & & 91,642 & \\
\hline$A A+$ prednisone annual $A E$ cost & & & -187 & 187 & & & \\
\hline Darolutamide annual AE cost & & & -141 & 141 & & & $\begin{array}{l}\text { Higher bound } \Delta \\
\text { Lower bound } \Delta\end{array}$ \\
\hline Apalutamide annual AE count & & & -92 & 92 & & & \\
\hline Enzalutamide annual AE cost & & & -89 & 89 & & & \\
\hline
\end{tabular}

$A A=$ abiraterone acetate $A E=$ adverse event

market share allocated to ADT alone (the least costly modeled treatment option).

The budget impact results (Table 1; Figure 2) show that total costs in the scenario with darolutamide were greater than total costs in the scenario without darolutamide in years 1 to 4 , but by year 5 , the reverse was true. The increase in total costs seen in the scenario with darolutamide was driven by increased drug acquisition costs; however, this increase was partially offset by reduced $\mathrm{AE}$ costs in each year. Additionally, in year 5, the market share of darolutamide compared with apalutamide was highest, and darolutamide had a less expensive annual cost than apalutamide and an estimated lower annual AE cost than apalutamide and enzalutamide. In terms of the per member per month (PMPM) cost, the model suggests that the payer can expect an approximate \$0.01 PMPM increase in budget in year 1 , which would be shifted to savings by year 5 (per treated member per month cost $=$ approximately $\$ 150$ in year 1 to $-\$ 40$ in year 5 ).

\section{ONE-WAY SENSITIVITY ANALYSIS}

A one-way sensitivity analysis was performed to test the robustness of the model results for year 1 and the sensitivity of these results to the uncertainty around cost input parameters and assumptions. The drug acquisition cost of darolutamide and AE costs in the model were varied by $\pm 20 \%$ of their default values.

Results of this analysis show that, of the parameters varied, variation of the drug acquisition cost of darolutamide had the most influence on the budget impact (Figure 3). Minimal changes were seen for the bounds for annual AE costs for $\mathrm{AA}+$ prednisone, darolutamide, apalutamide, and enzalutamide.

\section{SUBPOPULATIONS}

In addition to the base-case population (adult men with nmCRPC), the model included options to consider analyses focused on the subset of adult males with high-risk nmCRPC and those who were Medicare eligible. When a subpopulation was selected, the overall nmCRPC population was funneled down to the subgroup of patients who fit the selected criteria. The total patient counts and annual budget impact in each subpopulation are shown in Table 2 with the basecase results for comparison. Results in the subpopulations followed the same trends as those in the base case, with a spike in the budget impact in year 2 , followed by a decrease in years 3 and 4 and a cost savings in year 5 .

\section{Discussion}

The base-case model results indicate that adding darolutamide to a U.S. formulary as a therapeutic option for the treatment of nmCRPC would result in a manageable increase in the budget in the first 4 years after its introduction $(2.23 \%, 1.49 \%, 0.78 \%$, and $0.12 \%$ in years $1,2,3$, and 4 , respectively), followed by a $0.51 \%$ cost savings in year 5. The increased drug cost was the primary driver for the slight total cost increase. However, darolutamide has the lowest annual AE cost among the modeled treatments, and the reduction in $\mathrm{AE}$ costs (which grows as the market share of darolutamide increases over the time horizon) offsets a portion of the total cost increase. Results were consistent in the subpopulations of patients with high-risk nmCRPC and those who were Medicare eligible.

Budget impact analyses in nmCRPC are few, making it difficult to interpret the model results in light of existing evidence. To our knowledge, this is the first 


\section{TABLE 2 Subpopulation Budget Impact}

\begin{tabular}{|c|c|c|c|c|c|}
\hline Category & Year 1 & Year 2 & Year 3 & Year 4 & Year 5 \\
\hline \multicolumn{6}{|l|}{ Base-case analysis (nmCRPC) } \\
\hline Total patient count & 91 & 167 & 231 & 286 & 332 \\
\hline Annual budget impact (\$) & 158,640 & 200,539 & 150,697 & 28,901 & $-149,240$ \\
\hline \multicolumn{6}{|l|}{ High-risk nmCRPC } \\
\hline Total patient count & 45 & 74 & 91 & 102 & 109 \\
\hline Annual budget impact (\$) & 60,465 & 68,786 & 49,195 & 14,840 & $-27,258$ \\
\hline \multicolumn{6}{|l|}{ Medicare-eligible nmCRPC } \\
\hline Total patient count & 70 & 28 & 180 & 226 & 266 \\
\hline Annual budget impact (\$) & 120,566 & 154,254 & 117,402 & 22,821 & $-119,517$ \\
\hline
\end{tabular}

model exploring the budget impact of darolutamide in nmCRPC. The Institute for Clinical and Economic Review estimated the total potential budget impact for apalutamide and enzalutamide relative to continued ADT alone using WACs, estimated net prices, and prices needed to reach the $\$ 50,000$ per quality-adjusted life-year threshold. In their analysis, treating the entire eligible nmCRPC population with apalutamide or enzalutamide would result in a substantial budget impact. ${ }^{29}$

A previously published model estimated the budget impact of enzalutamide in high-risk nmCRPC. ${ }^{30}$ That study differs from the current study, as costs associated with progression to metastatic disease were incorporated and post-progression cost offsets were reported. Although patients who leave the target population (due to disease progression and/or death) are excluded from our analysis, progression is not incorporated in our model explicitly. Thus, no costs for monitoring or disease progression are included.

It should be noted that this model does not consider the clinical benefits of approved treatments for nmCRPC, as is usual for this type of analysis. Comprehensive economic assessments often include budget impact analyses, which focus on affordability in terms of costs, and cost-effectiveness analyses, which focus on value in terms of costs and health outcomes. ${ }^{10,31}$ Thus, while implications of adopting darolutamide for nmCRPC, we cannot make any assertions about the effectiveness of darolutamide relative to other treatments for nmCRPC. This type of comparison would be presented in a cost-effectiveness model.

All approved treatments (darolutamide, enzalutamide, and apalutamide) have demonstrated clinical benefits of delayed disease progression. ${ }^{5,19,20}$ Thus, without any head-to-head trials comparing these treatments, we have taken the conservative approach of not including any such treatment-specific efficacy parameters. While treatment-specific AEs were included, the criterion of grade 3-4 AEs occurring in at least $5 \%$ of patients for any treatment was enforced to avoid potential bias.

\section{LIMITATIONS}

Several considerations in our methodology could potentially affect the this analysis estimates the financial budget impact results. Pharmaceutical manufacturers may offer rebates and discounts to health plan sponsors for market access. However, these negotiations are private and confidential. ${ }^{32}$ Because we are not privy to the discounted prices available to payers, we use the publicly available WAC as recommended by the ISPOR task force on good budget impact modeling practices. ${ }^{10}$

In the base-case analysis, no discounts, rebates, or copayments associated with the acquisition of any medication or receipt of any treatment were considered. Under this assumption, we see the maximum possible budget impact results. The model is flexible, with customizability that enables the user to modify specific settings as additional data are available. For example, a 30\% discount on WAC for payers would translate to a decreased projected budget impact in each year of the analysis $(30.2 \%$, $30.9 \%$, $32.9 \%$, $56.1 \%$, and $22.4 \%$ in years $1-5$, respectively) compared with our base-case analysis with no discount. In the scenario with a $30 \%$ discount, payers could expect an increase in budget of less than \$0.01 PMPM in year 1 , which would shift to savings by year 5 .

Market share estimates for each scenario were estimated based on current and future projections from interview data (Bayer, data on file; January 2019). The market share inputs could potentially be updated with more informed data, which would provide a more accurate estimate of the budget impact. Subpopulation analysis results showed that a change in the model population would produce a change in the estimated number of patients affected by the introduction of darolutamide, which would change the magnitude of the budget impact.

This model allows for the consideration of treatment, administration, and $\mathrm{AE}$ costs. There may be additional cost 
differences that were not accounted for in the model, such as monitoring, resource utilization, or progression costs. In addition, $\mathrm{AE}$ costs are based on the assumption that all grade 3-4 AEs considered would results in hospitalization, as there are no data on the percentage of these events that actually result in hospitalization. This assumption could overestimate AE costs. Nevertheless, our base-case results represent the best approximation of the budget impact of darolutamide given the assumptions listed and inputs available.

\section{Conclusions}

This analysis shows that while adding darolutamide to a U.S. payer formulary for nmCRPC results in a minor increase in budget (year 1: 2.23\%), the increase trends downward and is cost saving by year $5(-0.51 \%)$. Darolutamide has a lower annual $\mathrm{AE}$ cost than the other modeled treatments; therefore, as the market share of darolutamide increases from $3.6 \%$ to $18.0 \%$, reduced $\mathrm{AE}$ costs offset increased drug costs. Results in the high-risk and Medicare-eligible subpopulations coincide with those in the overall nmCRPC population.

\section{DISCLOSURES}

This study was conducted by RTI Health Solutions under the direction of Bayer U.S. and was funded by Bayer U.S., which was involved in the design of the study; collection, analysis, and interpretation of the data; writing of the report; and the decision to submit the report for publication.

Miles and Purser (and/or their institutions) are employees of RTI Health Solutions and received research funding from Bayer U.S. to develop the budget impact model. Appukkuttan and Farej are employees of Bayer U.S. Wen was an employee of Bayer U.S. at the time of the study.

This study was presented as a poster at the AMCP Virtual Learning Event, April 20-24, 2020.

\section{ACKNOWLEDGMENTS}

Editorial services were provided by John Forbes and Bethan Pickering of RTI Health Solutions.

\section{REFERENCES}

1. American Cancer Society. Key statistics for prostate cancer. 2020. Accessed October 12, 2020. https://www.cancer. org/cancer/prostate-cancer/about/keystatistics.html

2. National Comprehensive Cancer Network (NCCN) Guidelines. Prostate cancer, version 2.2019. April 17, 2019. Accessed October 12, 2020. https://www. nccn.org/professionals/physician_gls/ default.aspx

3. Gustavsen G, Gullet L, Cole D, Lewine N, Bishoff JT. Economic burden of illness associated with localized prostate cancer in the United States. Future Oncol. 2020;16(1):4265-77.

4. Appukkuttan S, Tangirala K, Babajanyan S, Wen L, Simmons S, Shore N. A retrospective claims analysis of advanced prostate cancer costs and resource use. Pharmacoecon Open. Published online October 22, 2019. doi: 10.1007/s41669-019-00185-8

5. Fizazi K, Shore N, Tammela TL, et al.; ARAMIS Investigators. Darolutamide in nonmetastatic, castration-resistant prostate cancer. N Engl J Med. 2019;380(13):1235-46.

6. Bastos DA, Antonarakis ES.

Darolutamide for castration-resistant prostate cancer. Onco Targets Ther. 2019;12:8769-77.

7. U.S. Food and Drug Administration. FDA approves darolutamide for non-metastatic castration-resistant prostate cancer. Accessed October 12, 2020. https://www. fda.gov/drugs/resources-informationapproved-drugs/fda-approves-darolutamide-non-metastatic-castration-resistant-prostate-cancer
8. Moilanen A, Reetta Riikonen R, Riikka Oksala R, et al. Discovery of ODM-201, a new generation androgen receptor inhibitor targeting resistance mechanisms to androgen signaling-directed prostate cancer therapies. Sci Rep. 2015;5:12007.

9. American Cancer Society. Hormone therapy for prostate cancer. 2019.

Accessed October 12, 2020. https://www. cancer.org/cancer/prostate-cancer/ treating/hormone-therapy.html

10. Sullivan SD, Mauskopf JA, Augustovski F, et al. Budget impact analysis-principles of good practice: report of the ISPOR 2012 Budget Impact Analysis Good Practice II Task Force. Value Health. 2014;17(1):5-14.

11. U.S. Census Bureau. 2017 National population estimates. 2018. Accessed October 12, 2020. https://www.census.gov/data/ tables/2017/demo/popproj/2017-summary-tables.html

12. Tomaszewski EL, Moise P, Krupnick RN, et al. Symptoms and impacts in nonmetastatic castration-resistant prostate cancer: qualitative study findings. Patient. 2017;10(5):567-78.

13. Vespa J, Medina L, Armstrong DM. Demographic turning points for the United States: population projections for 2020 to 2060. Current population reports, P25-1144, U.S. Census Bureau. 2018. Accessed October 12, 2020. https:// www.census.gov/content/dam/Census/ newsroom/press-kits/2018/jsm/jsmpresentation-pop-projections.pdf

14. Kirby M, Hirst C, Crawford ED. Characterising the castration-resistant prostate cancer population: a systematic review. Int J Clin Pract. 2011;65(11):1180-92.

15. Small EJ, Saad F, Zheng Y, et al. Impact of intervening in high risk nonmetastatic castration-resistant prostate cancer (HRnmCRPC) on metastatic castrationresistant prostate cancer ( $\mathrm{mCRPC}$ ) disease burden. J Clin Oncol. 2018 36:(15 Suppl):e17010.

16. IBM Watson. IBM Micromedex. RED BOOK Online. [Database]. 2019. Accessed October 12, 2020. http://www.micromedexsolutions.com/ 
17. Optum 360. The essential RBRVS. A comprehensive listing of RBRVS values for CPT and HCPCS codes. 2019. American Medical Association; 2018.

18. U.S. Department of Health and Human Services. Common Terminology Criteria for Adverse Events (CTCAE) Version 4.0. Accessed October 12, 2020. https://evs.nci.nih.gov/ftp1/CTCAE/ CTCAE 4.03/CTCAE $4.03 \quad 2010-06-$ 14_QuickReference_5x7.pdf

19. Smith MR, Saad F, Chowdhury S, Oudard S, Hadaschik BA, Graff JN; SPARTAN Investigators. Apalutamide treatment and metastasis-free survival in prostate cancer. $\mathrm{N}$ Engl J Med. 2018;378(15):1408-18.

20. Hussain M, Fizazi K, Saad F, et al. Enzalutamide in men with nonmetastatic, castration-resistant prostate cancer. N Engl J Med. 2018;378(26):2465-74.

21. Ryan CJ, Crawford ED, Shore ND, et al. The IMAAGEN Study: effect of abiraterone acetate and prednisone on prostate specific antigen and radiographic disease progression in patients with nonmetastatic castration resistant prostate cancer. J Urol. 2018;200(2):344-52.

22. HCUPnet, Healthcare Cost and Utilization Project. Agency for Healthcare Research and Quality. Accessed October 12, 2020. http://hcupnet.ahrq.gov/
23. U.S. Bureau of Labor Statistics. Consumer price index. 2019. Accessed October 12, 2020. https://www.bls.gov/cpi

24. Lupron Depot (leuprolide acetate for depot suspension). Prescribing information. 2016. Accessed October 12, 2020. https://www.rxabbvie.com/pdf/lupronuro_pi.pdf

25. Zoladex (goserelin acetate implant) $3.6 \mathrm{mg}$. Prescribing information. 2017. Accessed October 12, 2020. http://documents.tersera.com/zoladex-us/3.6mg MagnumPI.pdf

26. Trelstar (triptorelin pamoate for injectable suspension). Prescribing information. 2018. Accessed October 12, 2020. https://www.accessdata.fda.gov/drugsatfda docs/label/2018/020715s040,0212 88s035,022427s015lbl.pdf

27. Firmagon (degarelix for injection). Prescribing information. 2016. Accessed October 12, 2020. http:// www.ferringusa.com/wp-content/ uploads/2018/04/2009054865-FirmagonPI-Rev.-05.2017.pdf

28. Zytiga (abiraterone acetate). Prescribing information. 2018. Accessed October 12, 2020. http://www.janssenlabels.com/package-insert/productmonograph/prescribing-information/ ZYTIGA-pi.pdf
29. Institute for Clinical and Economic Review. Antiandrogens for nonmetastatic castration-resistant prostate cancer. Final evidence report. October 2018. Accessed October 12, 2020. https://icer-review. org/wp-content/uploads/2018/02/ ICER Prostate Cancer Final Evidence Report 100418.pdf

30. Schultz NM, O'Day K, Sugarman R, Ramaswamy K. Budget impact of enzalutamide for nonmetastatic castrationresistant prostate cancer. J Manag Care Spec Pharm. 2020;26(4):538-49. doi: 10.18553/jmcp.2020.19329

31. U.S. Department of Veterans Affairs. Budget impact analysis. 2019. Accessed October 12, 2020. https://www. herc.research.va.gov/include/page. asp?id=budget-impact-analysis

32. Dusetzina SB, Conti RM, Yu NL, Bach $\mathrm{PB}$. Association of prescription drug price rebates in Medicare Part D with patient out-of-pocket and federal spending. JAMA Intern Med. 2017;177(8):1185-88. 